\title{
Genetic Diversity Study of African Rice (Oryza glaberrima) and its Wild Relatives using Microsatellites Markers
}

\author{
David Montcho ${ }^{1 *}$, Mounirou Sow ${ }^{2}$, Olufisayo Kolade ${ }^{3}$, Roland Bocco ${ }^{4}$ \\ and Clement Agbangla ${ }^{5}$
}

${ }^{1}$ Ecole de Gestion et de Production Végétale et Semencière, Université Nationale d'Agriculture BP 43 Ketou, Bénin.

${ }^{2}$ Sow AgriTech Ltd , Abdullahi Fodio Road, Opposite Government Technical College, Rumji Sambo, Sokoto, Nigeria.

${ }^{3}$ International Institute of Tropical Agriculture (IITA) PMB 5320, Oyo Road, Ibadan, Oyo State, Nigeria.

${ }^{4}$ Department of Agriculture and Natural Resources (ANR), UC Davis, Cooperative Extension 2156 Sierra Way, Ste C San Luis Obispo, CA 93401, United States. ${ }^{5}$ Université d'Abomey-Calavi, BP 526 Abomey-Calavi, Benin.

Authors' contributions

This work was carried out in collaboration among all authors. Author DM designed the study, wrote the protocol and wrote the first draft. Authors MS and OK performed the analysis of the study. Authors $R B$ and $C A$ revised the protocol and the manuscript. All authors read and approved the final manuscript.

Article Information

DOI: $10.9734 / A R R B / 2021 / v 36 i 530378$ Editor(s):

(1) Dr. Bechan Sharma, University of Allahabad, India. Reviewers:

(1) Essubalew Getachew Seyum, Jimma University,College of Agriculture and Veterinary Medicine, Ethiopia. (2) Faisul Ur Rasool, Skuast-K, India. Complete Peer review History: http://www.sdiarticle4.com/review-history/69110

Original Research Article

Received 26 March 2021

Accepted 01 June 2021

Published 08 June 2021

\section{ABSTRACT}

The Africa Rice Center Gene Bank hold about 2,500 accessions of Oryza glaberrima. To understand well the genetic diversity in O. glaberrima and its wild species, the use of molecular tools is prominent. The sample consisted of 217 accessions of $O$. glaberrima, 46 of $O$. barthii and 7 of $O$. sativa (checks) was genotyped with 21 polymorphic microsatellites markers. A total of 245 alleles were detected with average 11.67 alleles per locus. Number of alleles was ranged from 2 (RM124) to 20 (RM536). The polymorphic information content value was 0.49 while the heterozygosity was

*Corresponding author: E-mail: montchodav@yahoo.fr; 
0.091. The result showed that the sample can be clustered into four genotypic groups. Two groups among them were homogeneous. The first one consisted of 0 . barthii accessions with 82 alleles in total with average 3.90 alleles per locus. However, the second one consisted of only 0 . glaberrima accessions with 122 alleles with average 5.80 alleles per locus. O. glaberrima accessions were analyzed using model-based population structure. Results revealed two groups among 0 . glaberrima accessions. At the end, the identified core collection has 26 accessions consisted of 16 O. glaberrima and $10 \mathrm{O}$. barthii based on 21 microsatellites markers.

Keywords: African rice, alleles, genotypic groups, core collection.

\section{INTRODUCTION}

African Rice (Oryza glaberrima) is an important source for rice genetic improvement [1]. Before the introduction of $O$. sativa varieties by the Portuguese, O. glaberrima was domesticated from its wild ancestor (O. barthii) during the last 2,000 to 3,000 years in the inland delta of the upper Niger river which is well-known as Mali [2]. This specie was neglected by African farmers because of it low yielding due to high grains shattering and lodging susceptibility [3]. The interest of this specie increased with the finding which showed that $O$. glaberrima can be crossed with $O$. sativa by [4].

Moreover, O. glaberrima has many useful traits that can withstand abiotic stress such as, drought tolerance [5], submergence tolerance [6], tolerance to soil acidity, salt and iron toxicity $[7,8]$ and aluminium toxicity [9]. It was also reported that $O$. glaberrima is highly resistant to several diseases such as Rice yellow mottle virus [1012], blast [13], sheath blight, bacterial blight [14], and insect pests, nematodes [15,5], stem borer, hispa and stalked eye fly [16], African gall midge $[17,18]$ and weed competitiveness [19]. Some of the interesting traits of $O$. glaberrima were combined with high-yielding traits of $O$. sativa to develop the "New Rice for Africa" known as NERICA [4]. O. glaberrima accessions were considered as a rich genetic source to provide resistant genes to growth constraints. The gene bank of Africa Rice Center holds a collection of about 2,500 samples of African rice which still need to be fully characterized.

Using simple sequence repeats markers developed by $[20,21]$ revealed the population structure of 198 accessions of African Rice with 93 markers. In order to fully exploit the genetic diversity of this specie, the whole collection of 2,500 samples should be characterized and each sample assigned to the right genetic group. After using 74 accessions and 30 microsatellites markers, three genetic groups of African rice distinguished by [22]. Population structure of $O$. glaberrima was found to be homogeneous after using 20 accessions and 14 unlinked nuclear loci [23]. Likewise, Asian rice domesticated more than 10,000 years ago from 0 . rufipogon was characterized [24]. Therefore, the genetic diversity of $O$. sativa was performed by [25]. Those previous researchers detected five genetic groups corresponding to indica, aus, aromatic, temperate japonica, and tropical japonica rice. Gene bank of National Institute of Agrobiological Sciences in Japan holds 30,000 accessions of $O$. sativa. Previous study showed 69 varieties as a core collection from the 30000 accessions of 0 . sativa [26]. In order to fully exploit the genetic diversity of this specie, it would be preferable that the collection of 2500 in the Gene bank of the Africa Rice Center could be characterized, and each will be assigned to the right genetic group and identified the core collection. This study aimed to characterize 217 accessions of 0 . glaberrima and its wild ancestor and to establish the mini core collection as well using a set of 21 microsatellites markers.

\section{MATERIALS AND METHODS}

\subsection{Plant Materials}

Seeds of all genotypes (O. glaberrima, O. barthii and $O$. sativa) used in this study were kindly provided by the Gene bank of Africa Rice Center. Two hundred and seventeen accessions of $O$. glaberrima were selected to cover the geographic origins of African rice. Table 1 showed the frequencies based on the geographical distribution of different 0 . glaberrima accessions for this experiment. Additionally, from the Africa Rice Center, 46 accessions of $O$. barthii and 7 of $O$. sativa cultivars (Morobérékan, WAB56-104, Azucena, WITA4, B6144, IR64, and Basmati 370) as checks were used. 
Table 1. Distribution of plant material across geographic origins

\begin{tabular}{lll}
\hline Origin & Number of Accessions & Frequencies (\%) \\
\hline Burkina Faso & 4 & 1.84 \\
Cameroun & 1 & 0.46 \\
Côte d'Ivoire & 13 & 5.99 \\
Gambia & 11 & 5.07 \\
Ghana & 5 & 2.30 \\
Guinea & 8 & 3.69 \\
Liberia & 54 & 24.88 \\
Mali & 14 & 6.45 \\
Nigeria & 94 & 43.32 \\
Senegal & 6 & 2.76 \\
Sierra Leone & 6 & 2.76 \\
Total & 216 & 99.54 \\
Unknown & 1 & 0.46 \\
\hline
\end{tabular}

\subsection{Genotyping}

\subsubsection{DNA extraction}

Before the sowing date, seed dormancy of $O$. glaberrima was broken after removing its coat and cutting the opposite edge of the embryo. Four plantlets per sample were grown per pot (7.5 I each) in the greenhouse in Africa Rice Center (AfricaRice) station based in Cotonou (Bénin). From one month-old plant, young leaves were bulk harvested and frozen at $-20{ }^{\circ} \mathrm{C}$ until the DNA extraction [27]. Approximately $8 \mathrm{~cm}$ of leaf tissue was harvested and folded into $2 \mathrm{~mL}$ microfuge tubes above a pool of liquid nitrogen to freeze the tissue. In the AfricaRice biotechnology laboratory, the frozen tissue was crushed while $800 \mu \mathrm{l}$ of DNA extraction buffer $(100 \mathrm{mM}$ Tris- $\mathrm{HCl}$, $50 \mathrm{mM}$ EDTA, $500 \mathrm{mM} \mathrm{NaCl}, 1.25 \%$ (w/v) SDS, $3.8 \mathrm{~g}$ per $\mathrm{L}$ NaBisulfite) was added. Tubes were vortexed and incubated at $65^{\circ} \mathrm{C}$ for $20 \mathrm{~min}$. Subsequently, a chloroform extraction was performed with a $24: 1$ chloroform isoamyl alcohol solution, followed by ethanol precipitation and resuspension in $100 \mu \mathrm{l}$ of TE buffer. The DNA quality was determined by electrophoresis on $1 \%$ agarose gel stained with Gel Red and visualized under an transilluminator (Alpha Imager, Alphalnnotech). The DNA concentration was checked using Nanodrop (Thermo Scientific Nanodrop 8000 spectrophotometer ND-8000 V2.2.1) and the concentration was normalized by dilution to $25 \mathrm{ng} / \mu \mathrm{l}$.

\subsubsection{Capillary electrophoresis}

Based on the allele size published on the Gramene website (www.gramene.org/microsat/). 6 multiplex marker sets were composed using non-overlapping markers labelled with different dyes (Table 2). Markers were developed by [20]. The diluted DNA samples were subjected to PCR amplification (Bio-Rad 580BR 3770) using 21 microsatellites markers (Table 2). Markers were selected basis on the polymorphism they showed for early studies [21]. The sequences of the markers were available on the Gramene website (www.gramene.org/microsat/). The forward primer of each marker was labelled at the 5' end of the oligonucleotide with one of the following fluorescent dyes: 6-FAM (Blue), VIC (Green), NED (Yellow), PET (Red) (Applied Biosystems Inc., USA). PCR amplifications were performed according to the panel using 96-well plates. The total reaction volume of $25 \mu \mathrm{l}$ consisted of $3 \mu \mathrm{l}$ DNA, $1.25 \mu \mathrm{l}$ of each primer (forward and reverse), $12.5 \mu \mathrm{l}$ of master mix (dNTP, Taq DNA polymerase, and Buffer), and $7 \mu$ of pure water. Amplifications were carried out in a thermocycler (Bio-Rad 580BR 3770) using the following program: initial denaturing at $94^{\circ} \mathrm{C}$ for $5 \mathrm{~min}$ followed by 35 cycles of $94^{\circ} \mathrm{C}$ for $30 \mathrm{~s}, 55^{\circ} \mathrm{C}$ annealings for $30 \mathrm{~s}$ and $72^{\circ} \mathrm{C}$ for $30 \mathrm{~s}$ and a further primer extension at $72^{\circ} \mathrm{C}$ for $2 \mathrm{~min}$. Four randomly PCR products were migrated on agarose gel $1 \%$ to check the amplification. The master mix of $12 \mu \mathrm{l}$ consisted of $2 \mu \mathrm{l}$ diluted PCR product $(10 \%)$ and $10 \mu \mathrm{l}$ of formamide and GeneScan-500 LIZ size standard was prepared in optical 96-well MicroAmp plates (Applied Biosystems Inc., USA) for DNA fragments separation during electrophoresis. The master mix was then denatured at $94^{\circ} \mathrm{C}$ for 5 minutes. Fragment separation was performed using the ABI PRISM 3100 genetic analyzer machine containing POP 4 (performance optimized polymer) matrix and urea following the protocol developed by the AfricaRice Biotechnology unit. 
Table 2. Characteristics of selected markers and PCR strategy

\begin{tabular}{lllll}
\hline Multiplex & Markers & chromosomes & Allele size $(\mathrm{pb})$ & Dye color \\
\hline 1 & RM1 & 1 & $67-143$ & Green \\
& RM431 & 1 & $233-272$ & Yellow \\
& RM312 & 1 & $86-106$ & Yellow \\
& RM154 & 2 & $148-232$ & Blue \\
\hline 2 & RM14643 & 3 & $114-136$ & Yellow \\
& RM338 & 3 & $178-203$ & Yellow \\
& RM514 & 3 & $254-284$ & Red \\
& RM124 & 4 & $257-290$ & Yellow \\
& RM307 & 4 & $139-193$ & Green \\
& RM261 & 4 & $119-140$ & Blue \\
\hline 3 & RM510 & 6 & $129-145$ & Yellow \\
& RM152 & 8 & $133-157$ & Blue \\
& RM215 & 9 & $163-173$ & Green \\
\hline 4 & RM552 & 11 & $195-264$ & Red \\
& RM1227 & 12 & $141-163$ & Red \\
& RM19 & 12 & $192-267$ & Blue \\
& RM277 & 12 & $104-121$ & Red \\
& RM219 & 9 & $190-232$ & Green \\
\hline 5 & RM237 & 1 & $105-261$ & Blue \\
& RM536 & 11 & $223-247$ & Green \\
& RM44 & 8 & $111-151$ & Blue \\
\hline
\end{tabular}

\subsection{Molecular data analysis}

Molecular data were analyzed using Gene Mapper software version 4.0. (Applied Biosystems Inc., USA) A single or pair of peaks were detected. Fragments sizes were automatically generated with the reference to the internal size standard Gene Scan-500 LIZ from 35 to $500 \mathrm{pb}$. Eight accessions of O. glaberrima were excluded because of a high number of missing data (> 50\%). The statistical analysis was run using the 209 accessions and the 30 . sativa checks with the Gen Alex software [28] to eliminate redundant genotypes. Additionally, a genetic dissimilarity matrix was calculated based on the simple matching index using Darwin software [29]. The matrix was used for factorial analysis developed in Darwin. Genetic diversity of the collection, such as the number of alleles (Na), heterozygosity (Ho), Polymorphic Information Content (PIC), and gene diversity were estimated using Power Marker Version 3.25 [30]. The population structure of the samples was inferred using structure software version 2.3.3 [31]. The number of the population tested $(\mathrm{K})$ varied from 1 to 8 within 10 repetitions for each. The procedure was based on the burn-in period of 100000 and 500000 iterations of the MarkovChain Monte Carlo (MCMC) method [31]. The reel value of $\mathrm{K}$ was determined using the method of [32] based on the second-order rate of change of likelihood of data between consecutive $K$ values. Accessions with a probability of $98 \%$ of membership were assigned to the same group.

\section{RESULTS}

\subsection{Genetic Diversity in O. glaberrima and O. Barthii}

Genetic diversity was analyzed with 211 accessions of 0 . glaberrima, 7 varieties of 0 . sativa and 46 accessions of $O$. barthii using 21 microsatellites markers. Similarity analysis of the accessions showed that they differed at least by one allele. As a result, there is no redundant genotype and all genotypes were considered for the analysis.

Allelic diversity analysis revealed a total of 245 alleles with an average of 11.67 alleles per locus. For all markers tested, the number of alleles varied between 2 (RM124) and 20 (RM536). Markers such as RM14643, RM154, RM219, RM1, RM312, RM215, RM19, RM338, and RM536 revealed an above-average number of alleles per locus. The frequency of major alleles varied between 32.06 and $96.96 \%$ with an average of $60.23 \%$. In average, $60.23 \%$ of the 264 genotypes share a major allele common with each considered locus. The marker RM19 showed the lowest frequency while RM124 
showed the highest one. The molecular markers that showed an above-average major allele frequency are: RM307, RM1227, RM154, RM338, RM1, RM14643, and RM124. The Ho value varied between 0 and $50.20 \%$ with $9.13 \%$ on average. The weakest Ho value was determined by the marker RM124 (0\%) while the strongest one was revealed by the marker RM431 (50.2\%). The rate of polymorphism varied between 0.0572 (RM124) and 0.7624 (RM312) with 0.4877 on average. Among the 21 markers tested, those which showed a polymorphism rate higher than the average one are: RM277, RM237, RM44, RM431, RM414, RM261, RM219, RM536, RM19, RM312 (Table $3)$.

\subsection{Genotypic Diversity}

The result indicated that the samples in this study were divided into four genotypic groups (Fig. 1). Among the groups obtained, two were homogeneous. The genetic diversity (Table 4 ) for each of these groups was studied.

The first group showed $O$. barthii accessions with 82 total alleles with average of 3.90 alleles per locus. For the 21 markers tested, the number of alleles per locus varied between 0 and 11 . The marker RM536 showed high numbers of alleles per locus while the markers RM124, RM14643, RM152, and RM1227 showed a number of alleles equal to 0 . Ho rate varied between 0 and $61.90 \%$ and the marker RM338 indicated the highest amount. An average of $7.4 \%$ was obtained for the Ho mean value on the 21 markers tested. Additionally, PIC varied between 0 and $80.63 \%$ and RM536 presented the highest value. The lowest rate of polymorphism was obtained using the markers RM124, RM14643, RM152 and RM1227.

The second group pointed out only O. glaberrima accessions with 122 alleles and 5.80 alleles per locus as average. The number of alleles varied between 2 and 11 . The RM312 marker showed the highest number of alleles while the RM124 and RM552 markers indicated the lowest number of alleles. Ho values ranged between 0 and 0.67 with a mean rate of 0.096 . Some molecular markers like RM124, RM552, RM510, and RM215 have shown zero as Ho value. The RM431 marker showed the highest Ho value. Moreover, the polymorphism rate varied between 2.2 and $60 \%$ with an average estimated at 0.25 for the markers tested. The marker RM552 was identified as to which with the lowest rate of polymorphism while RM312 had shown the highest polymorphism.

Table 3. Genetic diversity of $O$. glaberrima and $O$. barthii accessions

\begin{tabular}{llllll}
\hline Markers & Ma & Na & Gd & Ho & PIC \\
\hline RM1 & 0.8372 & 14 & 0.2955 & 0.0426 & 0.2904 \\
RM154 & 0.7254 & 13 & 0.4593 & 0.0697 & 0.4440 \\
RM312 & 0.3548 & 14 & 0.7885 & 0.2823 & 0.7624 \\
RM431 & 0.5080 & 8 & 0.6347 & 0.5020 & 0.5737 \\
RM124 & 0.9696 & 2 & 0.0590 & 0.0000 & 0.0572 \\
RM14643 & 0.8829 & 12 & 0.2157 & 0.1587 & 0.2129 \\
RM261 & 0.4858 & 8 & 0.6590 & 0.0243 & 0.6047 \\
RM514 & 0.5240 & 13 & 0.6320 & 0.0320 & 0.5793 \\
RM307 & 0.6543 & 11 & 0.5088 & 0.0905 & 0.4546 \\
RM338 & 0.7386 & 19 & 0.4372 & 0.2917 & 0.4182 \\
RM510 & 0.5837 & 9 & 0.5605 & 0.0195 & 0.4923 \\
RM152 & 0.5891 & 9 & 0.5447 & 0.0271 & 0.4691 \\
RM215 & 0.5962 & 14 & 0.5395 & 0.0269 & 0.4646 \\
RM219 & 0.5382 & 13 & 0.6530 & 0.0305 & 0.6181 \\
RM19 & 0.3206 & 15 & 0.7360 & 0.0605 & 0.6896 \\
RM552 & 0.5633 & 11 & 0.5525 & 0.0082 & 0.4696 \\
RM1227 & 0.6641 & 10 & 0.4729 & 0.0742 & 0.3969 \\
RM277 & 0.5884 & 9 & 0.5666 & 0.0281 & 0.5054 \\
RM44 & 0.5224 & 10 & 0.6105 & 0.0650 & 0.5449 \\
RM237 & 0.5938 & 11 & 0.5755 & 0.0547 & 0.5241 \\
RM536 & 0.4087 & 20 & 0.7126 & 0.0278 & 0.6697 \\
Mean & 0.6023 & 11.667 & 0.5341 & 0.0913 & 0.4877 \\
\hline
\end{tabular}

Ma: Major allele; Na: Number of allele; Gd: Gene diversity; Ho: heterozygosity; PIC: Polymorphism Information Content 
Montcho et al.; ARRB, 36(5): 75-87, 2021; Article no.ARRB.69110

Table 4. Genetic diversity within each group

\begin{tabular}{|c|c|c|c|c|c|c|c|c|c|c|c|c|}
\hline \multirow[b]{2}{*}{ Marker } & \multicolumn{3}{|c|}{ Group 1} & \multicolumn{4}{|c|}{ Group 2} & \multicolumn{2}{|l|}{ Group 3} & \multicolumn{3}{|c|}{ Group 4} \\
\hline & $\mathrm{Na}$ & Ho & PIC & $\mathrm{Na}$ & Ho & PIC & $\mathrm{Na}$ & Ho & PIC & $\mathrm{Na}$ & Ho & PIC \\
\hline RM1 & 7 & 0 & 0.6820 & 8 & 0.0674 & 0.2131 & 5 & 0.0303 & 0.0930 & 7 & 0.0625 & 0.7164 \\
\hline RM154 & 5 & 0 & 0.6721 & 9 & 0.0833 & 0.3623 & 8 & 0.0565 & 0.2949 & 6 & 0.1250 & 0.7114 \\
\hline RM312 & 4 & 0 & 0.5921 & 11 & 0.1910 & 0.6045 & 12 & 0.4228 & 0.7530 & 4 & 0.0667 & 0.5508 \\
\hline RM431 & 3 & 0 & 0.4303 & 6 & 0.6705 & 0.5213 & 8 & 0.5040 & 0.6031 & 3 & 0.2 & 0.5194 \\
\hline RM124 & 1 & 0 & 0 & 2 & 0 & 0.0421 & 1 & 0 & 0 & 2 & 0 & 0.3524 \\
\hline RM14643 & 1 & 0 & 0 & 7 & 0.0588 & 0.0907 & 9 & 0.2180 & 0.2029 & 6 & 0.4286 & 0.5542 \\
\hline RM261 & 5 & 0.0526 & 0.6943 & 4 & 0.0128 & 0.5349 & 7 & 0.0226 & 0.5954 & 3 & 0.0588 & 0.2448 \\
\hline RM514 & 3 & 0.1 & 0.4553 & 8 & 0.0500 & 0.1638 & 4 & 0.0150 & 0.1228 & 4 & 0 & 0.6457 \\
\hline RM307 & 2 & 0 & 0.0866 & 6 & 0.2133 & 0.3226 & 3 & 0.0231 & 0.0374 & 3 & 0.1765 & 0.3749 \\
\hline RM338 & 9 & 0.6190 & 0.7077 & 7 & 0.0870 & 0.2144 & 9 & 0.4030 & 0.3792 & 6 & 0.1176 & 0.4250 \\
\hline RM510 & 4 & 0.1429 & 0.5162 & 4 & 0 & 0.1317 & 4 & 0.0149 & 0.0365 & 2 & 0 & 0.1861 \\
\hline RM152 & 1 & 0 & 0 & 6 & 0.0769 & 0.1812 & 2 & 0 & 0.0150 & 4 & 0 & 0.4791 \\
\hline RM215 & 3 & 0 & 0.1694 & 6 & 0 & 0.1437 & 2 & 0.0076 & 0.0076 & 8 & 0.3529 & 0.7664 \\
\hline RM219 & 4 & 0.0476 & 0.4666 & 5 & 0.0761 & 0.4655 & 2 & 0 & 0.0294 & 5 & 0 & 0.6849 \\
\hline RM19 & 5 & 0.1765 & 0.6833 & 5 & 0.0118 & 0.1209 & 6 & 0.0769 & 0.4284 & 7 & 0.0625 & 0.8033 \\
\hline RM552 & 3 & 0.0588 & 0.1572 & 2 & 0 & 0.0220 & 2 & 0.0081 & 0.0081 & 6 & 0 & 0.7125 \\
\hline RM1227 & 1 & 0 & 0 & 7 & 0.1905 & 0.1971 & 1 & 0 & 0 & 3 & 0.1765 & 0.1993 \\
\hline RM277 & 2 & 0.0625 & 0.0587 & 3 & 0.0556 & 0.3056 & 1 & 0 & 0 & 6 & 0.0625 & 0.6518 \\
\hline RM44 & 4 & 0.1875 & 0.4017 & 5 & 0.0930 & 0.1194 & 2 & 0.0391 & 0.2167 & 3 & 0.0000 & 0.4555 \\
\hline RM237 & 4 & 0.0556 & 0.2797 & 4 & 0.0330 & 0.4005 & 4 & 0.0455 & 0.0587 & 4 & 0.2667 & 0.5464 \\
\hline RM536 & 11 & 0 & 0.8063 & 7 & 0.0568 & 0.1083 & 8 & 0.0155 & 0.4870 & 5 & 0 & 0.5988 \\
\hline Means & 3.9048 & 0.0740 & 0.3743 & 5.8095 & 0.0966 & 0.2507 & 5 & 0.0906 & 0.2081 & 5 & 0.1027 & 0.5323 \\
\hline
\end{tabular}

Na: Number of allele; Ho: heterozygosity; PIC: Polymorphism Information Content 
The group 3 had consisted of both 0 . glaberrima and $O$. barthii. The total number of alleles revealed is equal to 100 with 4.76 alleles per locus on average. The number of alleles varied between 1 and 12 among the investigated samples. Markers RM124, RM1227, and RM277 indicated the lowest number of alleles while RM312 showed the highest one. Ho value fluctuated between 0 and $50 \%$ among the samples. Markers RM124, RM1227, RM277; RM152, and RM219 indicated low levels of Ho. The highest level of Ho value was obtained with the marker RM431 with an average of $9.1 \%$. The PIC varied between 0 and $75 \%$ with $21 \%$ on average. Markers RM124, RM1227 and RM277 showed zero as PIC and the RM312 marker indicated the highest one.

The group 4 includes the three species as $O$. glaberrima, $O$. barthii and $O$. sativa. The total number of alleles revealed was 97 with 4.61 alleles per locus on average. The number of alleles per locus varied between 2 and 8 . Markers RM124, and RM510 showed the lowest number of alleles while the marker RM215 indicated the highest one. The average Ho value determined using the 21 markers tested was estimated at $10.2 \%$. The highest Ho value was recorded on RM14643 (42\%) while the lowest one $(0 \%)$ was determined using markers RM124, RM510, RM44, RM514, RM152, RM219, RM536, and RM552. The rate of polymorphism varied between 19\% (RM510) and 80\% (RM19) with an average estimated at $53 \%$.

\subsection{Allelic Diversity Detected in 0 . glaberrima accessions}

Oryza glaberrima evaluated showed 203 as a total number of alleles $(\mathrm{Na})$. The $21 \mathrm{SSR}$ used detected 9.66 alleles per locus on average (Table 5). The number of alleles varied from 2 using RM124 marker to 14 using RM312. The frequency of the major allele $(\mathrm{Ma})$ ranged from 0.39 to 0.98 and with a mean value of 0.59 . The gene diversity (Gd) ranged from 2.8 to $74.9 \%$ with the mean value of 51.3. The heterogeneity (Ho) fluctuated between 0 to $62.4 \%$ with $9.9 \%$. as an average value. PIC value PIC was estimated at 0.45 and ranged from 0.027 to 0.72 .

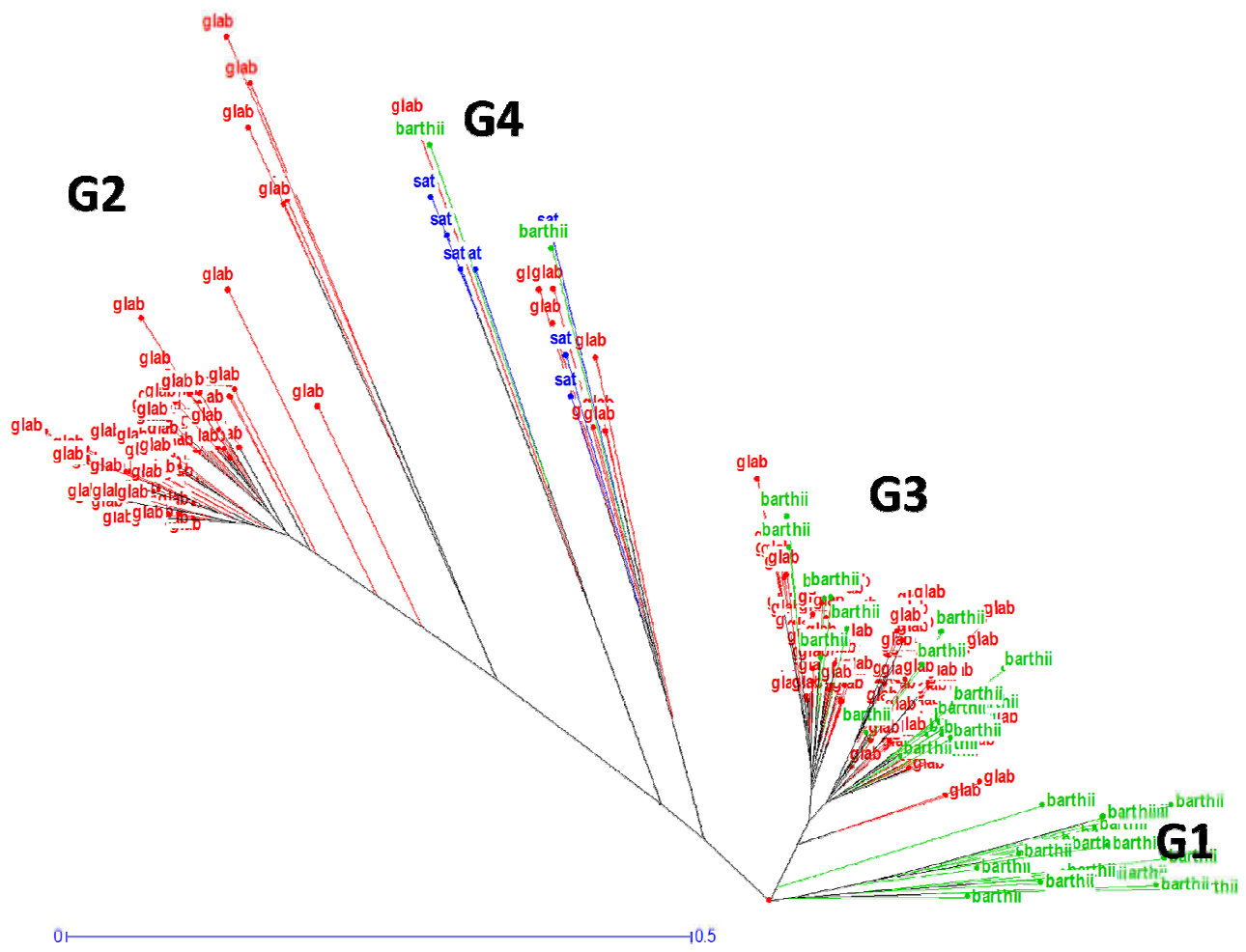

Fig. 1. Grouping base on 21 markers 


\subsection{Population Structure of O. glaberrima}

The 0 . glaberrima accessions used were analyzed by model-based population structure. $\mathrm{K}$ value is equal to 2 , consequently two populations were revealed in the all accessions tested (Figs. 2 and 3). The limit to assign a sample to a population was fixed at $98 \%$. The first population comprised 92 accessions with $44 \%$ of $O$. glaberrima. The genetic diversity indices of the two groups were summarized in Table 6. The two groups showed similar genetic diversity indices means as allele number, major allele frequency gene diversity Ho value and PIC. Nevertheless, some specific differences were found within the two groups based on microsatellites markers. RM19 and RM219 showed a high difference for major allele frequency and gene diversity. Moreover, the allele numbers for RM19, RM219 and RM124 were similar. Additionally, the Ho of markers such as RM312, RM14643 RM307 RM338, and RM1227 allowed the distinction of the two groups. Finally, PIC of RM14643, RM307, RM219, RM237, and RM536 differed for the two groups of $O$. glaberrima.

Table 5. Genetic diversity of 209 accessions of 0 . glaberrima using 21 SSR markers

\begin{tabular}{llllll}
\hline Markers & Ma & Na & Gd & Ho & PIC \\
\hline RM1 & 0.892 & 9 & 0.20 & 0.053 & 0.196 \\
RM154 & 0.823 & 12 & 0.313 & 0.066 & 0.300 \\
RM312 & 0.425 & 14 & 0.749 & 0.359 & 0.721 \\
RM431 & 0.484 & 8 & 0.650 & 0.624 & 0.590 \\
RM124 & 0.985 & 2 & 0.028 & 0.000 & 0.027 \\
RM14643 & 0.881 & 12 & 0.219 & 0.182 & 0.215 \\
RM261 & 0.497 & 6 & 0.647 & 0.025 & 0.590 \\
RM514 & 0.515 & 13 & 0.595 & 0.030 & 0.521 \\
RM307 & 0.584 & 11 & 0.556 & 0.105 & 0.485 \\
RM338 & 0.819 & 12 & 0.316 & 0.237 & 0.302 \\
RM510 & 0.573 & 7 & 0.520 & 0.004 & 0.421 \\
RM152 & 0.521 & 8 & 0.568 & 0.033 & 0.481 \\
RM215 & 0.536 & 13 & 0.547 & 0.019 & 0.452 \\
RM219 & 0.521 & 10 & 0.641 & 0.033 & 0.581 \\
RM19 & 0.391 & 10 & 0.691 & 0.044 & 0.632 \\
RM552 & 0.517 & 9 & 0.542 & 0.005 & 0.440 \\
RM1227 & 0.581 & 10 & 0.525 & 0.083 & 0.432 \\
RM277 & 0.526 & 8 & 0.597 & 0.029 & 0.526 \\
RM44 & 0.468 & 8 & 0.616 & 0.063 & 0.542 \\
RM237 & 0.531 & 10 & 0.608 & 0.053 & 0.545 \\
RM536 & 0.411 & 11 & 0.654 & 0.034 & 0.590 \\
Mean & $\mathbf{0 . 5 9 4}$ & $\mathbf{9 . 6 6 6}$ & $\mathbf{0 . 5 1 3}$ & $\mathbf{0 . 0 9 9}$ & $\mathbf{0 . 4 5 7}$ \\
\hline
\end{tabular}

Ma: Major allele; Na: Number of allele; Gd: Gene diversity; Ho: heterozygosity; PIC: Polymorphism Information Content

\subsection{Establishment of a Mini Core Collection}

The minimum number of accessions that would allow the diversity of the accessions tested to be grouped was established based on the size of alleles. Results revealed a mini core collection consisted of 26 accessions that include 160 . glaberrima and 10 O. barthii. Different identified groups during the study are mentioned in the mini core collection. The total number of alleles revealed by the core collection was 123 with an number of alleles in the core collection was estimated at $50.2 \%$ of the initial collection. Some parameters as gene diversity, $\mathrm{Ho}$, and PIC showed similar mean values for both core collection and all samples. Table 7 shows the comparison between the core collection and the global collection. average of 5.86 alleles per locus. The total 


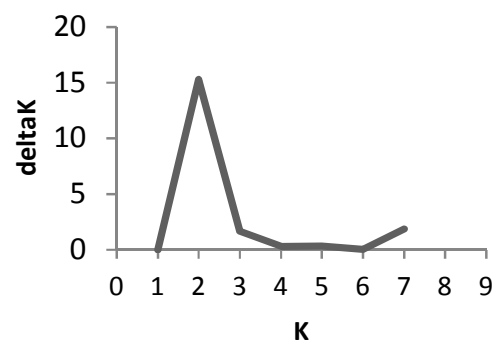

Fig. 2. Number of population detected

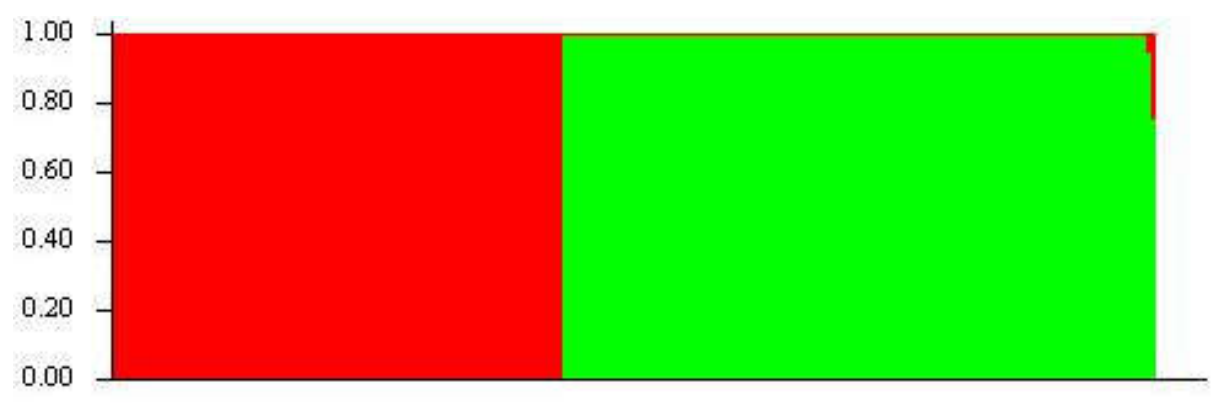

Fig. 3. Ancestries of 212 accessions from 21 SSR

Table 6. Genetic diversity between the two groups

\begin{tabular}{lcccccccccc}
\hline & \multicolumn{9}{c}{ Group 1 } & \multicolumn{5}{c}{ Group 2 } \\
\cline { 2 - 32 } Markers & Ma & Na & Gd & Ho & PIC & Ma & Na & Gd & Ho & PIC \\
\hline RM1 & 0.882 & 8 & 0.219 & 0.067 & 0.213 & 0.893 & 7 & 0.200 & 0.034 & 0.196 \\
RM154 & 0.780 & 9 & 0.379 & 0.083 & 0.362 & 0.857 & 7 & 0.257 & 0.045 & 0.244 \\
RM312 & 0.534 & 11 & 0.645 & 0.191 & 0.605 & 0.332 & 13 & 0.799 & 0.486 & 0.774 \\
RM431 & 0.591 & 6 & 0.576 & 0.670 & 0.521 & 0.391 & 8 & 0.688 & 0.573 & 0.626 \\
RM124 & 0.978 & 2 & 0.043 & 0.000 & 0.042 & 0.983 & 2 & 0.033 & 0.000 & 0.032 \\
RM14643 & 0.953 & 7 & 0.091 & 0.059 & 0.091 & 0.826 & 11 & 0.310 & 0.263 & 0.300 \\
RM261 & 0.583 & 4 & 0.587 & 0.013 & 0.535 & 0.437 & 6 & 0.674 & 0.025 & 0.614 \\
RM514 & 0.913 & 8 & 0.166 & 0.050 & 0.164 & 0.882 & 5 & 0.216 & 0.017 & 0.208 \\
RM307 & 0.800 & 6 & 0.344 & 0.213 & 0.323 & 0.957 & 5 & 0.084 & 0.034 & 0.083 \\
RM338 & 0.875 & 7 & 0.226 & 0.087 & 0.214 & 0.771 & 9 & 0.381 & 0.350 & 0.351 \\
RM510 & 0.929 & 4 & 0.135 & 0.000 & 0.132 & 0.983 & 3 & 0.033 & 0.008 & 0.033 \\
RM152 & 0.901 & 6 & 0.185 & 0.077 & 0.181 & 0.923 & 3 & 0.143 & 0.000 & 0.135 \\
RM215 & 0.923 & 6 & 0.146 & 0.000 & 0.144 & 0.962 & 7 & 0.075 & 0.026 & 0.075 \\
RM219 & 0.527 & 5 & 0.558 & 0.076 & 0.466 & 0.924 & 5 & 0.145 & 0.000 & 0.142 \\
RM19 & 0.935 & 5 & 0.124 & 0.012 & 0.121 & 0.521 & 5 & 0.551 & 0.068 & 0.454 \\
RM552 & 0.989 & 2 & 0.022 & 0.000 & 0.022 & 0.925 & 7 & 0.144 & 0.009 & 0.141 \\
RM1227 & 0.893 & 7 & 0.201 & 0.190 & 0.197 & 0.992 & 3 & 0.017 & 0.008 & 0.016 \\
RM277 & 0.794 & 3 & 0.341 & 0.056 & 0.306 & 0.932 & 6 & 0.130 & 0.009 & 0.127 \\
RM44 & 0.936 & 5 & 0.122 & 0.093 & 0.119 & 0.809 & 4 & 0.322 & 0.042 & 0.291 \\
RM237 & 0.731 & 4 & 0.435 & 0.033 & 0.400 & 0.953 & 6 & 0.091 & 0.059 & 0.090 \\
RM536 & 0.943 & 7 & 0.110 & 0.057 & 0.108 & 0.718 & 4 & 0.451 & 0.017 & 0.416 \\
Mean & $\mathbf{0 . 8 2 8}$ & $\mathbf{5 . 8 1}$ & $\mathbf{0 . 2 6 9}$ & $\mathbf{0 . 0 9 7}$ & $\mathbf{0 . 2 5 1}$ & $\mathbf{0 . 8 0 8}$ & $\mathbf{6 . 0}$ & $\mathbf{0 . 2 7 3}$ & $\mathbf{0 . 0 9 9}$ & $\mathbf{0 . 2 5 5}$ \\
\hline
\end{tabular}

Ma: Major allele; Na: Number of allele; Gd: Gene diversity; Ho: heterozygosity; PIC: Polymorphism Information Content 
Table 7. Comparison between mini core collection (MCC) and global collection (GC)

\begin{tabular}{lllllllll}
\hline & \multicolumn{3}{c}{ Na } & \multicolumn{2}{c}{ Gd } & \multicolumn{2}{c}{ Ho } & \multicolumn{2}{c}{ PIC } \\
\cline { 2 - 9 } Markers & MCC & GC & MCC & GC & MCC & GC & MCC & GC \\
\hline RM1 & 8 & 14 & 0.54 & 0.30 & 0.04 & 0.04 & 0.52 & 0.29 \\
RM154 & 7 & 13 & 0.61 & 0.46 & 0.09 & 0.07 & 0.59 & 0.44 \\
RM312 & 7 & 14 & 0.81 & 0.79 & 0.17 & 0.28 & 0.78 & 0.76 \\
RM431 & 3 & 8 & 0.66 & 0.63 & 0.33 & 0.50 & 0.58 & 0.57 \\
RM124 & 2 & 2 & 0.27 & 0.06 & 0 & 0 & 0.23 & 0.06 \\
RM14643 & 7 & 12 & 0.36 & 0.22 & 0.23 & 0.16 & 0.35 & 0.21 \\
RM261 & 5 & 8 & 0.68 & 0.66 & 0 & 0.02 & 0.63 & 0.60 \\
RM514 & 4 & 13 & 0.39 & 0.63 & 0.04 & 0.03 & 0.35 & 0.58 \\
RM307 & 8 & 11 & 0.68 & 0.51 & 0.35 & 0.09 & 0.65 & 0.45 \\
RM338 & 6 & 19 & 0.39 & 0.44 & 0.12 & 0.29 & 0.36 & 0.42 \\
RM510 & 4 & 9 & 0.43 & 0.56 & 0 & 0.02 & 0.40 & 0.49 \\
RM152 & 9 & 9 & 0.50 & 0.54 & 0.08 & 0.03 & 0.48 & 0.47 \\
RM215 & 8 & 14 & 0.67 & 0.54 & 0 & 0.03 & 0.65 & 0.46 \\
RM219 & 6 & 13 & 0.77 & 0.65 & 0.09 & 0.03 & 0.73 & 0.62 \\
RM19 & 6 & 15 & 0.53 & 0.74 & 0 & 0.06 & 0.51 & 0.69 \\
RM552 & 3 & 11 & 0.07 & 0.55 & 0.04 & 0.01 & 0.07 & 0.47 \\
RM1227 & 6 & 10 & 0.37 & 0.47 & 0.24 & 0.07 & 0.36 & 0.40 \\
RM277 & 3 & 9 & 0.49 & 0.57 & 0.13 & 0.03 & 0.43 & 0.51 \\
RM44 & 6 & 10 & 0.45 & 0.61 & 0.27 & 0.07 & 0.43 & 0.54 \\
RM237 & 7 & 11 & 0.73 & 0.58 & 0 & 0.05 & 0.70 & 0.52 \\
RM536 & 8 & 20 & 0.54 & 0.71 & 0.28 & 0.03 & 0.53 & 0.67 \\
Mean & $\mathbf{5 . 8 6}$ & $\mathbf{1 1 . 6 7}$ & $\mathbf{0 . 5 2}$ & $\mathbf{0 . 5 3}$ & $\mathbf{0 . 1 2}$ & $\mathbf{0 . 0 9}$ & $\mathbf{0 . 4 9}$ & $\mathbf{0 . 4 9}$ \\
\hline
\end{tabular}

Na: Number of allele; Gd: Gene diversity; Ho: heterozygosity; PIC: Polymorphism Information Content

\section{DISCUSSION}

The genetic diversity of $O$. glaberrima and its wild relatives are important for breeders to improve plants. The molecular characterization study allows to genetically investigate the African rice germplasm. In this study, 21 fluorescent microsatellites markers were tested on $O$. glaberrima. Among the sample evaluated, alleles detecting showed 3 to 14 alleles per locus (9.66 on average) with a total of 203 alleles. The average PIC found was 0.457 while the Ho value was estimated at 0.099. Compared to other studies on O. glaberrima, [21] analyzed 198 accessions with 93 microsatellites markers. Their results showed an average of 9.4 alleles per locus with a range from 2 to 27 alleles per locus while the mean PIC value was estimated at 0.34 and the $\mathrm{Ho}$ at 0.27 . [33] evaluated 26 accessions of 0 . glaberrima using 11 microsatellites markers. Those authors found on average 4 alleles associated with a PIC of 0.45 . During their study, [22] discovered that the number of alleles varied from 3 to 19 per locus (8.4 on average), a total number of alleles was estimated at 252 while the mean PIC was 0.52. Those authors used 74 samples of $O$. glaberrima associated with 30 fluorescent microsatellites markers. During their study, [34] found out an average of
4.94 alleles per locus and 0.31 as average PIC values in the $O$. glaberrima collection from Niger.

Results from the model-based population structure analysis showed the presence of two main genotypic groups $(\Delta \mathrm{k}=2)$. The structure analysis confirmed the two groups showed by factorial analysis using Darwin. The genetic diversity in each group indicated similar values for average of allele number per locus, $\mathrm{Ho}$ and PIC. In comparison to previous studies, [21] found out $\Delta \mathrm{k}=5$ which indicated five groups within the 198 O. glaberrima accessions. The difference between both studies can be explained by the highest density of markers for this purpose (93 vs 21). Previous studies revealed that it is a correlation between the number of genomic structures and density of markers. [35] showed that response obtained when increasing the marker density is largest when using a diverse training set to predict between poorly related material. Among the five genetically distinct groups, two admixtures groups were also identified sharing ancestry with O. sativa species. [22] also discovered three populations using 74 accessions and 30 SSR markers. The population structure mentioned by [36] was homogeneous with no obvious genetic subdivision. The present work indicated low 
diversity in O. glaberrima specie and confirmed previous findings. According to [36], the low genetic diversity of $O$. glaberrima would have been a genetic bottleneck during its domestication from a small initial population of $O$. barthii. The low diversity in $O$. glaberrima can also be explained by the low genetic diversity in O. barthii, the immediate ancestor of African rice, because $O$. barthii possessed the lowest nucleotide diversity for a wild plant species as reported by [37] and [38]. The low nucleotide diversity in $O$. glaberrima can therefore be explained by the severe genetic bottleneck it experienced during domestication [36]. Otherwise, self-pollination was found to be another factor leading to low diversity of 0 . barthii (wild of $O$. glaberrima) because it reduces effective population size and effective recombination rates and thus decreases diversity [39].

The mini core collection obtained from the global set gave 26 accessions including 160 . glaberrima and 10 O. barthii based on 21 microsatellites markers. The mini core collection identified can represent the whole accessions tested as show the diversity index; $\mathrm{Gd}(0.52$ vs $0.53)$, Ho (0.12 vs 0.09 ) and PIC (0.49 vs 0.49 ). The core collection is a limited set of accessions to represent the genetic spectrum of the whole collection [40]. In the end, 69 accessions were selected for the collection based on RFLP data from 332 accessions of $O$. sativa [26]. [41] were the first to highlight the need for a reference collection and suggest the idea of a "Core collection". According to these authors, setting up a core collection consists of obtaining a subsample of the basic collection presenting a maximum of diversity. With $10 \%$ of a collection, it is possible to conserve $75 \%$ of allelic diversity [42]. The long-term maintenance of the basic collections and their circulation between the continents justifies the creation of a core collection. The size of a core collection has long been a subject of debate [41]. However, in this study number of an allele in core collection is about $50 \%$ of the number of an allele of the global collection tested. The number of markers used should be increased to access more relevant information on the genetic diversity of $O$. glaberrima and its wild accessions.

\section{CONCLUSION}

Nowadays, African rice (Oryza glaberrima) becomes meaningful in breeding programs, but its genetic diversity is not well documented. This study focused on the genetic diversity assessment of 217 accessions from 0 . glaberrima; and 46 from $O$. barthii one using 21 microsatellites markers. Cluster results revealed 4 genotypic groups, while two were homogeneous based on allele frequencies. At the end, a mini core collection consisted of 26 accessions identified as representative of all tested accessions was established. This finding is a great contribution to rice improvement to control abiotic and biotic stresses which affect its production.

\section{ACKNOWLEGEMENTS}

This study was financially supported by the Ministry of Foreign Affairs, Japan and the Stresstolerant Rice for Africa and South Asia Project funded by the Bill and Melinda Gates Foundation. The authors would like to acknowledge this support with deep thanks.

\section{COMPETING INTERESTS}

Authors have declared that no competing interests exist.

\section{REFERENCES}

1 Wambugu PW, Ndjiondjop MN, Henry R. Genetics and Genomics of African Rice (Oryza glaberrima Steud) Domestication. Rice. 2021;14(1):1-14.

DOI: 10.1186/s12284-020-00449-6.

2 Linares OF. African rice (Oryza glaberrima): history and future potential Proc Natl Acad Sci. 2002;99:16360-16365.

3 Montcho D, Futakuchi K, Agbangla C, Fofana M, Dieng I. Yield loss of Oryza glaberrima caused by grain shattering under rainfed upland conditions. Int. J. Biol. chem. Sci. 2013;7:535-543.

4 Jones M, Dingkuhn M, Aluko SNM, Gabriel GT, Semon M. Interspecific Oryza Sativa L. $X$ O. Glaberrima Steud. progenies in upland rice improvement. Euphytica. 1997; 94(2):237-246.

DOI: 10.1023/a:1002969932224.

5 Maji T, Singh BN, Akenova ME. Vegetative stage drought tolerance in $O$. glaberrima Steud and $O$. sativa $L$. and relationship between drought parameters. Oryza. 2001; 38:17-23.

6 Futakuchi K. Submergence damage in rice and challenges in expanding the crop's adaptability to submerged conditions in West 
and Central Africa, in: Toriyama $\mathrm{K}$, et al. (Eds.), Rice is life: scientific perspectives for the 21st century, World Rice Research Conference, Tsukuba, Japan. 2005;445-448.

7 Nipah JO, Jones MP, Singh BN, Kantaka OS, Sahrawat KL. Screening for tolerance for iron toxicity Int. Rice Res. 1997;22:26 27.

8 Sahrawat KL, Sika M. Comparative tolerance of $O$. sativa and $O$. glaberrima rice cultivars for iron toxicity in West Africa. Int. Rice Res. Notes. 2002;27:30-31.

9 Baggie I, Zapata F, Sangina N. Genotypic response to aluminium toxicity of some rice International Rice Research Notes. 2002;27:42.

10 Albar L, Bangratz-Reyser M, Hébrard E, Ndjiondjop $M N$, Jones $M$, Ghesquière $A$. Mutations in the elF(iso)4G translation initiation factor confer high resistance of rice to Rice yellow mottle virus. Plant Journal. 2066; 47:417 - 426.

11 Ndjiondjop MN, Fargette D, Fauquet C, Ghesquiere A. The genetic basis of high resistance to rice yellow mottle virus (RYMV) in cultivars of two cultivated rice species. Plant disease. 1999; 83(10):931-935.

12 Thiémélé $D$, Boisnard $A$, Ndjiondjop $M N$, Chéron S, Séré Y, Aké S. Identification of a second major resistance gene to Rice yellow mottle virus RYMV2 in the African cultivated rice species, O. glaberrima. TAG Theoretical and Applied Genetics. 2010;121(1):169-179. DOI: 10.1007/s00122-010-1300-2.

13 Silue D, Notteghem J. Resistance of 990. glaberrima varieties to blast. Int. Rice Res. Notes. 1991;16:13-14.

14 Djedatin G, Ndjiondjop MN, Mathieu T, Cruz CMV, Sanni A, Ghesquière AA, et al. Evaluation of African cultivated rice Oryza glaberrima for resistance to bacterial blight. Plant disease. 2011;95(4):441-447.

DOI: $10.1094 /$ pdis-08-10-0558.

15 Lorieux M, Reversat G, Garcia DSX, Denance $\mathrm{C}$, Jouvenet $\mathrm{N}$, Orieux $\mathrm{Y}$, et al. Linkage mapping of $\mathrm{Hsa}-1 \mathrm{Og}$, a resistance gene of African rice to the cyst nematode, Heterodera sacchari. Theoretical and Applied Genetics. 2003;107:691 - 696.

16 Alam MS, Efron Y. Resistance to stalk eyed fly, Diopsis macroptholma. Dalman. Int. Rice Commun. Newsl. 1986;31:40-45.

17 Nwilene FE, Williams UT, Ukwangwu MN, Dakouo D, Nacro S, Hmadoun A, et al. Reactions of differential genotypes to African gall midge in West Africa. Intel. Pest Manag. 2002;48:195-201.
18 Williams CT, Hidievbie O, Ukwungwu MN, Dakouo D, Nacro S, Hamadoun A. Multilocational screening of $O$. sativa and $O$. glaberrima for resistance to African gall midge O. oryzovora. Int. Rice Res. Notes. 1999;24:26-27.

19 Moukoumbi YD, Sie M, Vodouhe R, Bonou W, Toulou B, Ahanchede A. Screening of rice varieties for their weed competitiveness. African Journal of Agricultural Research. 2011; 6:5446 - 5456.

20 McCouch SR, Teytelman L, Xu Y, Lobos KB, Clare K, Walton M, et al. Development and mapping of 2240 new SSR markers for rice (Oryza sativa L.). DNA Res. 2002;9:199-207.

21 Semon M, Nielsen R, Monty J, McCouch SR. The Population Structure of African Cultivated Rice Oryza glaberrima (Steud.) Evidence for Elevated Levels of Linkage Disequilibrium Caused by Admixture with $O$. sativa and ecological Adaptation. Genetics. 2005;169:1639-1647.

DOI: 10.1534/genetics. 104.033175.

22 Dramé KN, Sanchez I, Gregorio G, Ndjiondjop MN. Suitability of a selected set of simple sequence repeats (SSR) markers for multiplexing and rapid molecular characterization of African rice (Oryza glaberrima Steud.). African Journal of Biotechnology. 2011;10(35):6675-6685. DOI: 10.5897/AJB10.2279.

$23 \mathrm{Li}, \mathrm{Z}$, Zheng X, Ge S. Genetic diversity and domestication history of African rice (Oryza glaberrima) as inferred from multiple gene sequences. Theor. Appl. Genet. 2001a; 123:21 - 31 .

24 Kovach MJ, Sweeney MT, McCouch SR. New insights into the history of rice domestication. Trends in Genetics. 2007; 23:578-587.

DOI: 10.1016/j.tig.2007.08.012.

25 Garris AJ, Tai HT, Coburn J, Kresovich S, McCouch S. Genetic Structure and Diversity in Oryza sativa L. Genetics. 2005;169:16311638.

DOI: 10.1534/genetics.104.035642.

26 Kojima Y, Ebana K, Fukuoka S, Nagamine T, Kawase M. Development of an RFLP-based Rice Diversity Research Set of Germplasm. Breeding Science. 2005;55(4):431-440. DOI: $10.1270 / j s b b s .55 .431$.

27 Risterucci AM, Grivet L, N‘Goran JAK, Pieretti I, Flament $\mathrm{MH}$, Lanaud C. A highdensity linkage map of Theobroma cacao L. Theor. Appl. Genet. 2000;101:948-955.

28 Peakall R, Smouse PE, Genalex 6: genetic analysis in Excel. Population genetic 
software for teaching and research. Mol. Ecol. Notes. 2006;6:288 - 295.

29 Perrier X, Jacquemoud-Collet JP. DARwin software. CIRAD, Montpellier, France; 2006. Available:http://darwin.cirad.fr/darwin. Accessed 30 Oct 2010.

30 Liu K, Muse SV. PowerMarker: integrated analysis environment for genetic marker data. Bioinformatics. 2005;21:2128-2129.

DOI: $10.1093 /$ bioinformatics/bti282.

31 Pritchard JK, Stephens M, Donnelly P. Inference of population structure using multilocus genotype data. Genetics. 2000; 155:945 -959.

32 Evanno G, Regnaut S, Goudet J. Detecting the number of clusters of individuals using the software structure: a simulation study. Mol. Ecol. Notes. 2005;14:2611-2620.

33 Barry MB, Pham JL, Noyer JL, Billot C, Courtois B, Ahmadi N, 2007. Genetic diversity of the two cultivated rice species $(O$. sativa \& O. glaberrima) in Maritime Guinea. Evidence for interspecific recombination. Euphytica. 2007;154:127-137.

DOI: doi 10.1007/s10681-006-9278-1.

34 Sow M, Ndjiondjop MN, Sido A, Mariac C, Laing M, Bezançon G. Genetic diversity, population structure and differentiation of rice species from Niger and their potential for rice genetic resources conservation and enhancement. Genetic Resources and Crop Evolution. 2014;61(1):199-213.

DOI: 10.1007/s10722-013-0026-9.

35 Norman A, Taylor J, Edwards J, Kuchel H. Optimising genomic selection in wheat: Effect of marker density, population size and population structure on population accuracy. G3: Genes, Genomesn Genetics. 2018;8(9): 2889-2899.

36 Li, ZM, Zheng XM, Ge S. Genetic diversity and domestication history of African rice (Oryza glaberrima) as inferred from multiple gene sequences. Theoretical and Applied Genetics. 2011b;123(1):21-31.

DOI: $10.1007 / \mathrm{s} 00122-011-1563-2$.

37 Haudry A, Cenci A, Ravel C, Bataillon T, Brunel D, Poncet C, et al. Grinding up wheat: a massive loss of nucleotide diversity since domestication. Mol. Biol. Evol. 2007;24:1506 $-1517$.

38 Zhang XC, Wu XL, Findley S, Wan J, Libault M. Molecular evolution of lysin motif-type receptor-like kinases in plants Plant Physiol. 2007; 144:623.

39 Charlesworth D. Effects of inbreeding on the genetic diversity of populations Phil Trans $R$ Soc Lond B. 2003;358:1051-1070.

40 Frankel OH. Genetic perspectives of germplasm conservation.In "Genetic manipulation: impact on man and society" Arber WK, Limensee KL, Peacock WJ, Stralinger $P$ (eds.), Cam-bridge University Press, Cambridge. 1984;161-170.

41 Frankel $\mathrm{OH}$, Brown AHD. Current plant genetic resources--a critical appraisal. In Genetics: new frontiers: proceedings of the XV International Congress of Genetics/editors, Chopra VL, et al. New Delhi: Oxford \& IBH Publishing Co.; 1984.

42 Brown AHD. Core collections: a practical approach to genetic resources management. Genome. 1989;31(2):818-824.

(c) 2021 Montcho et al.; This is an Open Access article distributed under the terms of the Creative Commons Attribution License (http://creativecommons.org/licenses/by/4.0), which permits unrestricted use, distribution, and reproduction in any medium, provided the original work is properly cited.

Peer-review history:

The peer review history for this paper can be accessed here: http://www.sdiarticle4.com/review-history/69110 